\title{
Os Institutos Federais de Educação, Ciência e Tecnologia como vetores de desenvolvimento no estado do Rio de Janeiro: a perspectiva de gestores de unidades
}

Les Instituts Fédéraux de l'Education, des Sciences et de la Technologie en tant que vecteurs de développement dans l'état de Rio de Janeiro: la perspective des responsables d'unités

Los Institutos Federales de Educación, Ciencia y Tecnología como vectores de desarrollo en el estado de Río de Janeiro: la perspectiva de gestores de unidades The Federal Institutes of Education, Science and Technology as vectors of development in the state of Rio de Janeiro: the perspective of unit managers

\section{Mauro Sergio Pinheiro dos Santos de Souza}

\section{(2) OpenEdition}

\section{Journals}

\section{Edição electrónica}

URL: http://journals.openedition.org/espacoeconomia/5757

DOI: 10.4000/espacoeconomia.5757

ISSN: 2317-7837

\section{Editora}

Núcleo de Pesquisa Espaço \& Economia

\section{Refêrencia eletrónica}

Mauro Sergio Pinheiro dos Santos de Souza, « Os Institutos Federais de Educação, Ciência e Tecnologia como vetores de desenvolvimento no estado do Rio de Janeiro: a perspectiva de gestores de unidades », Espaço e Economia [Online], 14 | 2019, posto online no dia 11 agosto 2019, consultado o 04 setembro 2019. URL : http://journals.openedition.org/espacoeconomia/5757 ; DOI : 10.4000/ espacoeconomia. 5757

Este documento foi criado de forma automática no dia 4 Setembro 2019. 


\section{Os Institutos Federais de Educação, Ciência e Tecnologia como vetores de desenvolvimento no estado do Rio de Janeiro: a perspectiva de gestores de unidades}

Les Instituts Fédéraux de l'Education, des Sciences et de la Technologie en tant que vecteurs de développement dans l'état de Rio de Janeiro: la perspective des responsables d'unités

Los Institutos Federales de Educación, Ciencia y Tecnología como vectores de desarrollo en el estado de Río de Janeiro: la perspectiva de gestores de unidades The Federal Institutes of Education, Science and Technology as vectors of development in the state of Rio de Janeiro: the perspective of unit managers

Mauro Sergio Pinheiro dos Santos de Souza

\section{Introdução}

1 O programa de expansão sistemática da rede federal de ensino profissional, empreendido pelo Governo Federal a partir de 2005, foi concebido como um dos vetores estratégicos da política pública de Educação para o desenvolvimento local e regional no País, visando a formação de profissionais qualificados para atender às especializações e características da economia local e regional. Entendia-se que a expansão e a desconcentração espacial da rede possibilitariam que as instituições federais de ensino se tornassem estratégicas para o desenvolvimento territorial, na medida em que propiciariam novas possibilidades às localidades e regiões atendidas. 
2 Num panorama amplo, o desenvolvimento econômico e social brasileiro, além de multivariados fatores, sofre com os efeitos do baixo nível da educação de sua população, que repercute na parca capacidade produtiva de inovações técnicas e tecnológicas, ainda marcadamente produzidas no âmbito universitário. Esse quadro da educação nacional, por outro lado, dificulta a superação de carências econômicas e de se empreender novos meios para o fortalecimento na geração de riquezas nas diferentes localidades do País. Em vista disso, não é demais lembrar que as instituições de ensino também são relevantes no desenvolvimento local e regional (ALBUQUERQUE, 2004; SEN, 2010) e, assim, é oportuno investiga-las como vetores de desenvolvimento.

3 As desigualdades persistentes no território nacional refletem esse problema, pois as instituições educativas mais prestigiosas e que têm maior capacidade de gerar inovações que favoreçam as economias locais e regionais, ou nacional, se localizam, historicamente, em poucas áreas do território. A Constituição de 1988, por outro lado, repartiu as responsabilidades de promoção da educação entre os entes federados, tendo por noção a "competência comum" entre os entes, ou seja, um ente poderia atuar prioritariamente sobre um ciclo, ao mesmo tempo em que o outro também poderia fazê-lo (ABRUCIO, 2010). Nessa medida, a União reforçou sua atuação no sistema educativo nacional, ao ampliar a rede federal de ensino profissional da qual é mantenedora, ao mesmo tempo em que buscou fomentar novos modos de atuação da rede em benefício das economias locais e regionais, sobretudo a partir da criação dos Institutos Federais de Educação, Ciência e Tecnologia, em 2008.

4 O modo de atuação do Estado está num contexto de mudanças econômicas mais amplas, em que os diferentes territórios são engajados na competição econômica local, regional/ nacional e global (BECKER, 2009; RÜCKERT, 2004). O Estado brasileiro, na concepção dessas instituições, visou, concomitantemente, formar profissionais técnicos e de nível superior capazes de contribuir com o desenvolvimento local e regional, estimular a produção de inovações científico-tecnológicas e atender a demandas locais e regionais. Por isso, o nome dessas instituições é intencional: devem buscar articular a educação, em especial a educação profissional, com a produção de ciência e tecnologia, em contraste com o papel das antigas escolas técnicas federais.

Em vista dessas considerações, o estado do Rio de Janeiro foi contemplado com a criação de dois institutos federais: o do Rio de Janeiro e o Fluminense. As novas figuras institucionais foram formadas a partir dos antigos CEFET Química e CEFET-Campos, além dos Colégios Agrícolas vinculados à Universidade Federal Fluminense-UFF, acrescidos das novas unidades criadas com a expansão da rede federal. A partir de uma metodologia qualitativa, buscamos entender como os gestores de alguns campi percebem a atuação das unidades por eles geridas no desenvolvimento do estado do Rio de Janeiro.

6 Assim, a pesquisa apresentada, que deriva da dissertação que defendi em 2016, propõe-se a refletir o papel dos Institutos Federais de Educação no desenvolvimento local e regional, a partir das realidades vivenciadas por essas instituições no território fluminense. 0 artigo foi dividido em duas partes, além da introdução e considerações finais: na primeira, apontamos os aspectos metodológicos da pesquisa realizada; na segunda, ao trazermos as percepções dos gestores dos institutos, realizamos considerações sobre os discursos dos gestores. 


\section{Aspectos metodológicos da pesquisa} de campi dos institutos federais e a percepção a respeito do papel desempenhado pela unidade do Instituto Federal no desenvolvimento local e regional. É importante ressaltar que a entrevista semiestruturada permite ao pesquisador abordar as questões que lhe interessam compreender na investigação científica, assim como possibilita ao entrevistado expor suas opiniões e relatos, de modo mais livre, do que aquele empreendido na entrevista estruturada.

As entrevistas semi-estruturadas combinam perguntas abertas e fechadas, onde o informante tem a possibilidade de discorrer sobre o tema proposto. $O$ pesquisador deve seguir um conjunto de questões previamente definidas, mas ele o faz em um contexto muito semelhante ao de uma conversa informal. 0 entrevistador deve ficar atento para dirigir, no momento que achar oportuno, a discussão para o assunto que o interessa fazendo perguntas adicionais para elucidar questões que não ficaram claras ou ajudar a recompor o contexto da entrevista, caso o informante tenha "fugido" ao tema ou tenha dificuldades com ele. Esse tipo de entrevista é muito utilizado quando se deseja delimitar o volume das informações, obtendo assim um direcionamento maior para o tema, intervindo a fim de que os objetivos sejam alcançados. (BONI E QUARESMA, 2005, p. 75).

abordagem qualitativa que utilizamos na pesquisa permite que se trabalhe com o universo dos significados, dos motivos, das aspirações, das crenças, dos valores, das atitudes (MINAYO, 1994).

Esse conjunto de fenômenos humanos é entendido aqui como parte da realidade social, pois o ser humano se distingue não só por agir, mas por pensar sobre o que faz e por interpretar suas ações dentro e a partir da realidade vivida e partilhada por seus semelhantes. $O$ universo da produção humana que pode ser resumido no mundo das relações, das representações e da intencionalidade e é objeto da pesquisa qualitativa dificilmente pode ser traduzido em números e indicadores quantitativos. (MINAYO, 1994, p. 21).

Assim, a escolha do método do qualitativo nos permite aprofundar sobre a compreensão dos atores entrevistados a respeito do papel da instituição, a partir de informações e dados advindos da entrevista dos que atuam localmente. Fizemos a escolha de entrevistarmos os diretores gerais e, em alguns casos, os diretores de ensino, a respeito da relevância do Instituto Federal como partícipe do desenvolvimento territorial.

0 recorte dos atores entrevistados se deve, primordialmente, ao papel que diretoresgerais exercem na instituição: atuam localmente ao vivenciarem as relações que se constroem no cotidiano da unidade da instituição, ao mesmo tempo em que se articulam aos demais diretores de unidades, à Reitoria, aos atores locais e regionais existentes. Nesse sentido, os diretores-gerais são a interface mais importante entre a realidade e as demandas localmente existentes e o conjunto da instituição, em especial em relação ao alto escalão representado pela Reitoria e os grupos de decisão da instituição.

É relevante recordar, no entanto, que os demais atores envolvidos com a instituição, e/ou que se beneficiam dos serviços oferecidos pela instituição, também importam para a percepção do desenvolvimento local e regional, ainda que não tenham sido contemplados em nossa pesquisa. Além disso, faz-se necessário frisar que a percepção dos diretores 
resulta dos valores, crenças, atitudes etc. que refletem e/ou são reflexo de um dado momento sócio-histórico e sócio espacial.

Por ocasião de realização das entrevistas, estabelecemos um Roteiro de Entrevista com perguntas que versaram sobre diversas temáticas de interesse em nossa pesquisa, assim como possibilitamos aos diretores tecerem, livremente, considerações sobre o papel desempenhado pelos Institutos Federais. As perguntas de nosso roteiro visaram entender como os gestores percebem a importância do Instituto Federal para o desenvolvimento socioeconômico do município, da região e do estado do Rio de Janeiro.

As entrevistas foram realizadas nos meses de maio, junho e julho de 2016, sendo que do total de 23 campi dos Institutos Federais do estado do Rio de Janeiro existentes à época (Imagem 1), nove foram visitados para a realização de entrevistas. A escolha das unidades buscou contemplar as diferentes regiões do estado do Rio de Janeiro. Assim, com exceção da mesorregião Centro Fluminense, todas as demais mesorregiões foram visitadas: Metropolitana, Sul Fluminense, Norte Fluminense, Baixadas e Noroeste Fluminense.

Imagem 1. Mapa da distribuição dos Institutos Federais e CEFET/RJ no estado do Rio de Janeiro por Micro e Mesorregião (2016)

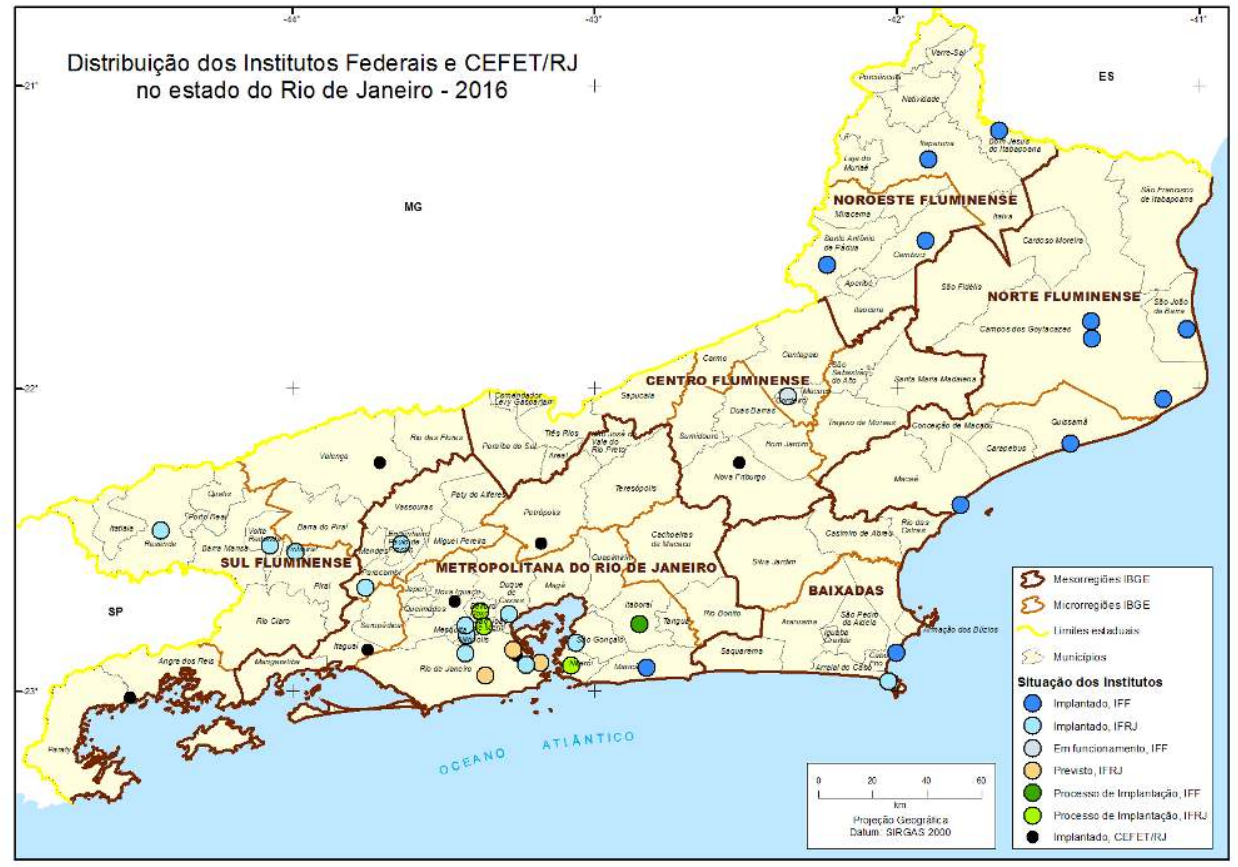

FONTE: ELABORADO PELO AUTOR, COM BASE NOS DADOS ColetAdOS E DO IBGE (2016).

Parte considerável dos gestores já havia exercido outras funções dentro dos Institutos Federais, na maioria dos casos na própria unidade que dirigem e, em alguns poucos casos, em outras unidades. Com isso, indica-se que os diretores, antes de exercerem o cargo máximo na unidade, usualmente já possuem vivência da realidade institucional e, também, há aqueles que permanecem ministrando aulas, o que enriquece a percepção que possuem do Instituto.

O quadro (imagem 2) apresenta uma visão geral do perfil dos entrevistados, com um total de 11 participantes. Ressalta-se que apenas três ingressaram nos Institutos Federais antes 
do programa de expansão. Além disso, usamos no decorrer do trabalho a abreviação "DG" quando se refere ao cargo de direção-geral e "DE” quando se refere à direção de ensino.

Imagem 2. Quadro da relação de entrevistas nos Institutos Federais do estado do Rio de Janeiro

\begin{tabular}{|c|c|c|c|c|c|c|}
\hline Inst. & Campus & Cargo & $\begin{array}{c}\text { Ingresso no } \\
\text { Instituto }\end{array}$ & $\begin{array}{l}\text { Função na } \\
\text { Direção }\end{array}$ & $\begin{array}{c}\text { Início na } \\
\text { Direção }\end{array}$ & $\begin{array}{c}\text { Data de } \\
\text { Entrevista }\end{array}$ \\
\hline \multirow[t]{6}{*}{ IFF } & \multirow{2}{*}{$\begin{array}{l}\text { Bom Jesus } \\
\text { do } \\
\text { Itabapoana }\end{array}$} & $\begin{array}{l}\text { Professor do Ensino } \\
\text { Básico, Técnico e } \\
\text { Tecnológico }\end{array}$ & 2010 & Diretor-Geral & 2016 & $17 / 06 / 2016$ \\
\hline & & $\begin{array}{l}\text { Professor do Ensino } \\
\text { Básico, Técnico e } \\
\text { Tecnológico }\end{array}$ & 2010 & $\begin{array}{l}\text { Diretor de } \\
\text { Ensino }\end{array}$ & 2016 & $17 / 06 / 2016$ \\
\hline & Cabo Frio & $\begin{array}{l}\text { Professor do Ensino } \\
\text { Básico, Técnico e } \\
\text { Tecnológico }\end{array}$ & 2008 & Diretor-Geral & 2016 & $21 / 06 / 2016$ \\
\hline & $\begin{array}{l}\text { Campos } \\
\text { dos } \\
\text { Goytacazes } \\
\text {-Centro }\end{array}$ & $\begin{array}{l}\text { Professor do Ensino } \\
\text { Básico, Técnico e } \\
\text { Tecnológico }\end{array}$ & 1991 & Diretor-Geral & 2016 & $24 / 06 / 2016$ \\
\hline & Itaperuna & $\begin{array}{l}\text { Professor do Ensino } \\
\text { Básico, Técnico e } \\
\text { Tecnológico }\end{array}$ & 2008 & Diretor-Geral & 2012 & $20 / 06 / 2016$ \\
\hline & $\frac{\frac{\text { Santo }}{\text { Antônio }}}{\text { Pádua }}$ de & $\begin{array}{l}\text { Técnico em Assuntos } \\
\text { Educacionais }\end{array}$ & 2010 & Diretor-Geral & 2016 & $20 / 06 / 2016$ \\
\hline \multirow[t]{5}{*}{ IFRJ } & $\begin{array}{l}\text { Engenheiro } \\
\text { Paulo de } \\
\text { Frontin }\end{array}$ & $\begin{array}{l}\text { Professor do Ensino } \\
\text { Básico, Técnico e } \\
\text { Tecnológico }\end{array}$ & 2006 & Diretor-Geral & 2009 & $07 / 07 / 2016$ \\
\hline & Maracanã & $\begin{array}{l}\text { Professor do Ensino } \\
\text { Básico, Técnico e } \\
\text { Tecnológico }\end{array}$ & 1995 & Diretor-Geral & 2014 & $30 / 06 / 2016$ \\
\hline & \multirow{2}{*}{ Nilópolis } & $\begin{array}{l}\text { Professor do Ensino } \\
\text { Básico, Técnico e } \\
\text { Tecnológico }\end{array}$ & 2008 & $\begin{array}{l}\text { Diretor de } \\
\text { Ensino }\end{array}$ & 2014 & $31 / 05 / 2016$ \\
\hline & & $\begin{array}{l}\text { Professor do } \\
\text { Magistério Superior }\end{array}$ & 2007 & Diretor-Geral & 2014 & $02 / 06 / 2016$ \\
\hline & Pinheiral & $\begin{array}{l}\text { Professor do Ensino } \\
\text { Básico, Técnico e } \\
\text { Tecnológico }\end{array}$ & 1997 & Diretor-Geral & 2014 & $28 / 06 / 2016$ \\
\hline
\end{tabular}

Fonte: elaborado pelo autor (2016).

As entrevistas foram gravadas com autorização verbal dos respectivos entrevistados, com exceção das entrevistas realizadas com os Diretores de Ensino e Geral do campus Nilópolis. É interessante notar que há vantagens e desvantagens na gravação da entrevista, o que observamos no decorrer da pesquisa.

A maior vantagem da gravação, a nosso ver, foi permitir revisitar o que fora dito pelo entrevistado, em seu espaço de vivência da instituição, a fim de extrair elementos que podem passar despercebidos quando anotado diretamente pelo pesquisador, ou que sofram a interferência do pesquisador ao registrar. No entanto, a gravação inibe, aparentemente, que observações mais espinhosas a respeito de problemas, críticas ou dilemas existentes sejam realizadas e, não poucas vezes, notamos que os entrevistados utilizavam da gravação como uma espécie de "porta-voz" de certas indignações que decorrem do cotidiano por eles vivenciado. À vista disso, elaboramos uma síntese das informações fornecidas nas entrevistas dos diretores a respeito da percepção que eles tinham do papel dos institutos no desenvolvimento socioeconômico local, regional e estadual. 


\section{O papel dos institutos no desenvolvimento socioeconômico local, regional e estadual}

19 De modo unânime, os diretores entendem que o Instituto Federal é uma instituição importante no desenvolvimento local, regional e estadual. Nesse sentido, a Instituição é relevante em vista da "perspectiva de elevação de escolaridade, de formação profissional dos alunos" (DG-Rio de Janeiro), o que traz "muita transformação por conta da instituição, muitas pessoas entrando no mercado de trabalho" (DG-Cabo Frio) e que, por isso, "hoje tem a chance de melhorar a renda da família" (DG-Itaperuna). Majoritariamente, os aspectos que foram citados para explicar o porquê de perceberem a instituição como relevante no desenvolvimento: a elevação da formação dos discentes e a possibilidade de ingresso no mercado de trabalho.

20 Porém, além da formação dos discentes - uma das atividades fim -, cita-se o impacto gerado pelo instituto na economia local e regional a partir da criação de empregos diretos e indiretos (seja por realização da obra de construção da unidade, seja por contratação de profissionais para atuarem no instituto - professores, seguranças, atendentes etc.). Nesse sentido, destacamos a fala de DG-Itaperuna:

E uma pergunta é socioeconômico, né, em relação, na sociedade de maneira geral, é o fato do nosso Instituto aqui, quando a gente tem as obras, quantos e quantos empregos são criados aqui, os próprios, hoje o concurso aqui é por núcleo, empregando pessoas aqui da região, só no nosso Instituto nós temos 120 servidores mais cerca de 40 profissionais contratados, então eu acredito que além da atividade fim o Instituto também tem um impacto gigantesco, né, na economia por meio de empregos diretos e indiretos.

21 A escala regional nas atividades do instituto aparece em todas as falas dos diretores. $\mathrm{Na}$ visão de um dos gestores o papel do Instituto no município e na região é importante

porque o Instituto Federal na região do Noroeste Fluminense ele abre muitas possibilidades pra todos os munícipes aqui de Santo Antônio de Pádua ou da região, então, sim, é muito relevante a vinda de uma instituição desse porte para um município do interior. Aí nessa questão, assim, do desenvolvimento socioeconômico do município, o Noroeste Fluminense ele tem como característica econômica a área de serviços e comércio, foi até nesse intuito de que nós colocamos aqui, por exemplo, curso técnico em administração e logística, né, que são cursos que de alguma forma dialogam com essa característica econômica do Noroeste Fluminense. (DG-Santo Antônio de Pádua)

22 No entanto, a escala regional não se limita tão somente ao estado do Rio de Janeiro, ao abranger, por exemplo, municípios do Espírito Santo e de Minas Gerais.

[...] então eu considero sim que o instituto aqui em Pádua pensando na microrregião nossa, que atende Itaocara, que atende Miracema, Aperibé e Minas Gerais, que o município de Pirapitinga, nós vamos contribuir muito para o desenvolvimento dessa região sim. (DG-Santo Antônio de Pádua)

Ademais, interessante notar que, para DG-Santo Antônio de Pádua, a microrregião do Instituto abrange os municípios de Miracema (RJ), Aperibé (RJ) e, também, Pirapitinga (MG). Assim, ainda que a expansão sistemática da rede federal de ensino profissional tenha sido estabelecida com base na mesorregião e na microrregião definidas pelo IBGE restrita aos limites estaduais-, em realidade, a atuação das unidades do Instituto ultrapassa essas limitações que decorrem dos critérios elencados para a expansão da rede (SOUZA, 2016). 
24 A relevância do Instituto Federal no desenvolvimento do estado do Rio de Janeiro se dá pela "união dos Institutos, aí Instituto Federal Fluminense, Instituto Federal do Rio de Janeiro e o CEFET, sem dúvida, tem um padrão muito bom de ensino, e também o mesmo papel social em todos esses lugares" (DG-Cabo Frio). De acordo com DG-Pinheiral, o Instituto é relevante, pois

oferece curso em várias áreas, cursos técnicos, graduação, licenciatura, pósgraduação, é sem dúvida nenhuma que a gente tem dado uma colaboração importante no estado do Rio de Janeiro, ainda é pouco conhecido enquanto marca, as universidades são muito mais marcantes, mas já consegue dar sua contribuição significativa.

Na perspectiva do DG-Santo Antônio de Pádua, o instituto é importante no desenvolvimento do estado porque o aluno formado tem o mundo do trabalho a conquistar. Essa importância aparece no médio e longo prazo, e colaborará com o estado do Rio de Janeiro.

[...] Eu vejo, assim, essa questão mais pra nossa característica do noroeste fluminense, qual que é a relevância? Relevância total no momento que você traz uma formação técnica para um município do interior, como é nosso caso em Santo Antônio de Pádua, isso lógico a médio e longo prazo vai colaborar com o estado do Rio de Janeiro, mesmo que esse aluno não atue em Santo Antônio de Pádua ou noroeste fluminense, tem o mundo do trabalho pra conquistar [...] institutos sem precedentes para o desenvolvimento [...] no Noroeste Fluminense temos muitos problemas [...] relevância total... (DG-Santo Antônio de Pádua)

Reforça essa perspectiva a DG-Rio de Janeiro, para quem houve uma mudança qualitativa no papel desempenhado pela instituição na formação dos discentes no desenvolvimento: buscam-se melhores processos, mais eficazes, através de uma formação "mais atualizada". Para a DG, a instituição se manteve importante no desenvolvimento do estado do Rio de Janeiro, desde quando a instituição foi criada para atender ao setor industrial.

Bom, o Instituto Federal desde a sua origem lá na antiga escola técnica, né, e pela sua própria origem, ele foi gerado exatamente para o desenvolvimento das indústrias, lá na origem, por questões políticas e históricas, né, no momento da Guerra, e hoje visando a busca de melhores processos, processos mais eficazes, né, a mudança mesmo de comportamento das indústrias que fazem com que o estado do Rio se desenvolva, né, na busca de um melhor processo ambiental, de uma produção mais rápida e eficiente, com maior qualidade, então, é a presença do instituto gerando uma formação maior, melhor, mais atualizada sempre vai ajudar no desenvolvimento do estado do Rio de Janeiro, no momento em que ele interfere no desenvolvimento da sua indústria, no mercado de trabalho, seja no terceiro setor, ou mesmo na área de serviços.

É importante notar que em todos os casos os diretores apontaram que os formados não necessariamente atuam no município ou na região, mas se dispersam para outros lugares do estado do Rio de Janeiro, ou mesmo fora do estado, especialmente onde há mais oferta de empregos. Nesse sentido, revela-se que nem sempre a escala local e regional se beneficiará da formação do discente. Para isso, é necessário criar as sinergias com a base produtiva local (VÁZQUEZ-BARQUERO, 2002; ALBAGLI \& MACIEL, 2004), com o poder público, ou seja, "o instituto tem que dialogar mais com o setor produtivo...às vezes o empresário local não conhece a nossa instituição" (DG-Santo Antônio de Pádua).

Além disso, com base nos dados fornecidos nas entrevistas, compilamos os municípios que foram referenciados pelos diretores como aqueles de origem dos discentes. A proporção de alunos de cada município mencionado varia, mas essa informação serve para indicar a larga abrangência de atuação das unidades. 
Por outro lado, quanto aos discentes formados, houve maior dificuldade em indicar os municípios onde os alunos trabalham após serem formados, uma vez que não há um acompanhamento sistemático dos egressos. Porém, é possível notar que os formados atuam em diversos municípios no estado do Rio de Janeiro e, também, em outros estados (Imagem 3).

Imagem 3. Quadro de municípios de abrangência dos Institutos Federais fluminenses

\begin{tabular}{|c|c|c|}
\hline Campus & Municípios de residência dos discentes & $\begin{array}{l}\text { Municípios onde os discentes } \\
\text { formados trabalham }\end{array}$ \\
\hline $\begin{array}{l}\text { Bom Jesus do } \\
\text { Itabapoana }\end{array}$ & $\begin{array}{l}\text { Bom Jesus do Itabapoana (RJ), Apiacá (ES), São } \\
\text { José do Calcados (ES), Bom Jesus do Norte } \\
\text { (ES), Caiana (MG), Carangola (MG) Varre-Sai } \\
\text { (RJ), Itaperuna (RJ), distritos de Campos dos } \\
\text { Goytacazes (RJ) }\end{array}$ & $\begin{array}{l}\text { Campos dos Goytacazes (RJ), } \\
\text { municipios de Minas Gerais, } \\
\text { municipios do Espirito Santo }\end{array}$ \\
\hline Cabo Frio & $\begin{array}{l}\text { Cabo Frio (RJ), Búzios (RJ), São Pedro da } \\
\text { Aldeia (RJ), Arraial do Cabo (RJ), Iguaba (RJ), } \\
\text { Rio das Ostras (RJ), Casimiro de Abreu (RJ), } \\
\text { Saquarema(RJ) }\end{array}$ & $\begin{array}{l}\text { Municípios da Região dos } \\
\text { Lagos, Búzios, Cabo Frio, Rio } \\
\text { de Janeiro, Macaé }\end{array}$ \\
\hline $\begin{array}{l}\text { Campos dos } \\
\text { Goytacazes-Centro }\end{array}$ & $\begin{array}{l}\text { Campos dos Goytacazes (RJ), São João da Barra } \\
\text { (RJ), Itaperuna (RJ), Santo Antônio de Pádua } \\
\text { (RJ), São Fidélis (RJ), Macaé (RJ), Cardoso } \\
\text { Moreira (RJ), Italua (RJ) }\end{array}$ & $\begin{array}{l}\text { Campos dos Goytacazes, Macaé, } \\
\text { São João da Barra, Quissamã, } \\
\text { outros lugares do Brasil }\end{array}$ \\
\hline $\begin{array}{l}\text { Engenheiro Paulo de } \\
\text { Erontin }\end{array}$ & $\begin{array}{l}\text { Engenheiro Paulo de Frontin (RJ), Paracambi } \\
\text { (RJ), Vassouras (RJ), Miguel Pereira (RJ), Paty } \\
\text { do Alferes (RJ), Valença (RJ), Mendes (RJ), Rio } \\
\text { de Janeiro (RJ), São Paulo, Minas Gerais }\end{array}$ & $\begin{array}{l}\text { Engenheiro Paulo de Frontin } \\
\text { em outras áreas }\end{array}$ \\
\hline Itaperuna & $\begin{array}{l}\text { Itaperuna (RJ), Porciúncula (R), Natividade } \\
\text { (RJ), Laje do Muriaé (RJ), Miracema (RJ), } \\
\text { Tombos (MG), Italya(RJ), Cardoso Moreira (RJ) }\end{array}$ & $\begin{array}{l}\text { Macaé, Prefeituras, Itaperuna, } \\
\text { Santo Antônio de Pádua, Macaé, } \\
\text { Niterói, Campos dos Goytacazes }\end{array}$ \\
\hline Nilópolis & $\begin{array}{l}\text { Nilópolis (RJ), Mesquita (RJ), Nova Iguaçu (RJ), } \\
\text { Zona Norte do Rio de Janeiro (RJ), São Jão de } \\
\text { Meriti (RJ), Duque de Caxias (RJ), Queimados } \\
\text { (RJ) }\end{array}$ & $\begin{array}{l}\text { Belford Roxo, Nova Iguaçu, } \\
\text { Duque de Caxias, São João de } \\
\text { Meriti }\end{array}$ \\
\hline Pinheiral & $\begin{array}{l}\text { Volta Redonda (RJ), Barra do Piraí (RJ), } \\
\text { Pinheiral (RJ), Valencaa (RJ), Barra Mansa (RJ), } \\
\text { Pirai (RJ), Quatis (RJ), Mendes (RJ), Engenheiro } \\
\text { Paulo de Exontin (RJ), Rio das Flores (RJ), Santa } \\
\text { Rita de Jacutinga (MG), Rio Preto (MG), } \\
\text { Cruzeiro (SP), Queluz (SP) }\end{array}$ & $\begin{array}{l}\text { Em muitos municíios } \\
\text { diferentes }\end{array}$ \\
\hline $\begin{array}{l}\text { Rio de Janeiro } \\
\text { (Maracanã) }\end{array}$ & $\begin{array}{l}\text { Rio de Janeiro (RJ), Região Metropolitana, } \\
\text { Baixada Fluminense, Niterói (RJ), São Gonçalo } \\
\text { (RJ), Paracambi (RJ), Japeri (RJ) }\end{array}$ & $\begin{array}{l}\text { Jacarepaguá (Rio de Janeiro), } \\
\text { Belford Roxo, Duque de Caxias } \\
\text { (Petróleo), Itaguaí, Nova Iguaçu, } \\
\text { São João de Meriti, Niterói, São } \\
\text { Gonçalo, Campos dos } \\
\text { Goytacazes, Macaé, Volta } \\
\text { Redonda, Petrópolis }\end{array}$ \\
\hline $\begin{array}{l}\text { Santo Antônio de } \\
\text { Pádua }\end{array}$ & $\begin{array}{l}\text { Santo Antônio de Pádua (RJ), Itaocara (RJ), } \\
\text { Aperibé (RJ), Miracema (RJ), Pirapitinga (MG), } \\
\text { Palma (MG), Recreio (MG) }\end{array}$ & Sem alunos formados \\
\hline
\end{tabular}

Fonte: elaborado pelo autor (2016).

O papel em rede dos Institutos Federais aparece em várias falas, uma vez que além das unidades atraírem a população local e regional, elas traçam estratégias para não haver concorrência entre si e o público atendido, no caso das unidades que se localizam próximo. Assim, a proximidade de algumas unidades faz com que a abrangência da rede se sobreponha em alguma medida, com discentes oriundos dos mesmos municípios. Ao perguntarmos ao DG-Pinheiral se haveria concorrência com o campus Volta Redonda, do mesmo instituto, devido à proximidade, fomos informados que:

Não exatamente, nós somos complementares, nós não somos concorrentes, então, Volta Redonda oferece cursos na área de metrologia e técnico em elétrica, eletrotécnica, são cursos que praticamente não tem nada a ver o que nós temos aqui no campus Pinheiral, Resende está um pouco mais longe tá oferecendo Segurança do Trabalho e Guia de Turismo, que também não tem nada a ver com os cursos oferecidos aqui no campus Pinheiral... nós somos complementares...(DG-Pinheiral)

31 Em Cabo Frio, a relação entre o IFF-Cabo Frio e o IFRJ-Arraial do Cabo, municípios vizinhos, aparece na fala do entrevistado, uma vez que o IFF-Cabo Frio "não abre curso igual ao de Arraial do Cabo e vice-versa [...] não sobrepõe a atuação de um sobre o outro, um participa no conselho de campus do outro". Assim, cada unidade da rede, além de atender ao município e aos municípios próximos, articulando-os e atraindo os potenciais 
alunos do município e da região, também age conjuntamente com as outras unidades para não haver sobreposição de atuação.

Além da importância da oferta de cursos no desenvolvimento local e regional, a articulação com outros atores também aparece, ao estabelecer convênio com secretarias locais e escolas municipais:

A gente já vê muita transformação por conta da instituição [..] na área de hospitalidade e lazer é a única instituição que realmente forma profissionais nessa área, não tem outro que forme nessa área, é uma demanda regional muito forte, na parte de indústria nossos alunos ocupam os cargos nas empresas rapidamente, tem uma ascensão boa, e, sem falar na interação com outras instituições, escolas do município, a gente tem vários convênios com a secretaria de educação, turismo também, é...a gente traz muitos alunos das escolas públicas do município, não só de Cabo Frio, mas dos outros municípios para cá, pros laboratórios e tal... (DG-Cabo Frio)

Nessa perspectiva, a abrangência das unidades muda conforme os cursos ofertados. Segundo os entrevistados, os cursos técnicos atraem mais a população local e regional, além de ter se modificado o padrão socioeconômico dos discentes dos cursos técnicos, em especial nos municípios onde há uma concorrência maior para ingresso na instituição. Aponta DG-Campos-Centro:

o que acontecia antigamente, o Instituto Federal Fluminense era taxado como uma escola da elite. Por que da elite? Porque uma escola com ensino de qualidade e gratuito...uma escola que tem ensino gratuito e de qualidade, ela é bem procurada. Então, o que acontecia, quando você fazia um processo seletivo aqui, a procura era muito grande...e aí acabava entrando aqui aqueles alunos que estavam mais preparados e vinham praticamente das escolas particulares...não quer dizer que a escola pública ela não... não tínhamos alunos da escola pública, mas era uma minoria, maioria escola particular, então a escola ficou um pouco elitizada...[...] e qual avanço também? A Lei das Cotas. Quando ele põe $50 \%$ de cotas, né, isso permitiu que o aluno, que não tava numa condição, assim, muito igualitária daquele da escola particular tivesse acesso a escola...então, hoje eu posso até dizer a você que, hoje, pelo que a gente conversa com a assistência estudantil que a gente tem aqui dentro, que a maioria hoje é mais carente, a gente conseguiu reverter esse quadro [...].

34 Já DG-Cabo Frio informou que "a gente atende também diferentes classes, nossos estudantes são bem diversificados... entrada pelas cotas, entrada de muitos alunos através desse sistema, muitos alunos formados nas escolas municipais da região... mas também tem aluno de escola particular... bem diversificado...".

Em Bom Jesus do Itabapoana, os cursos ofertados possuem um público diverso socialmente que inclui, de acordo com os gestores, o "filho do médico" e o "filho do faxineiro". Além disso, os diretores chamam a atenção para essas diferenças sociais:

[...] tem que ver esse aluno que veio d'um colégio lá de uma roça...cidadezinha pequinininha, da zona rural, colégio humilde, que é essa questão, professores não são tão valorizados, aí cai aqui dentro, um professor que acabou de terminar um doutorado, mecanismo, de muito conteúdo, a gente tem que ver isso ae, vamos equilibrar isso aí...precisa fazer com que esse aluno te acompanhe... (DE-Bom Jesus do Itabapoana)

Os cursos de graduação têm uma parcela de discentes com melhores condições socioeconômicas do que as dos estudantes do ensino técnico. Além disso, dependendo do curso de graduação ofertado, atraem-se alunos oriundos de municípios mais distantes e, inclusive, de fora do estado. Em parte isso se explica porque os Institutos selecionam os 
alunos da graduação pelo Sistema de Seleção Unificada (SiSU), do Ministério da Educação, que possui abrangência nacional. Assim, possibilita-se que o aluno ingressante na unidade seja de qualquer parte do País.

[...] a questão da graduação, que aqui, por exemplo, se fala muito da questão local, do município, e da questão regional, quando a gente parte pra graduação, com o sistema do SiSU, o próprio ENEM, ele deixa um... ele abrange essa ideia de regional, porque do mesmo jeito que nós temos alunos, ex-alunos, que hoje estão estudando no Mato Grosso, Rio Grande do Sul, Maranhão, Ceará, Bahia, Viçosa, Lavras etc. com a graduação no SiSU, via SiSU, a gente pretende receber alunos de outros estados também...ou seja, uma coisa que já aconteceu lá atrás com o curso técnico, que acabou, com a proliferação dos Institutos Federais pelo Brasil todo, é... com a graduação a gente tem a expectativa de que a gente vai retornar a receber alunos tanto do estado do Rio de Janeiro quanto de outros estados...né... Ela não é... ela [graduação] deixa de ser local/regional, ela passa a ser praticamente nacional...20\%, em alguns estados, acho que no Paraná, tá em torno de $40 \%$ dos alunos ingressantes nas universidades públicas do Paraná são de outros estados... (DG-Pinheiral)

$\mathrm{Na}$ visão dos diretores sobre a relação do município onde está o campus com os municípios circunvizinhos existem variações. Segundo os Diretores de Nilópolis, Engenheiro Paulo de Frontin e Pinheiral, os municípios onde estão localizadas as unidades são cidadesdormitório. Os demais municípios do Noroeste Fluminense, Campos dos Goytacazes, Cabo Frio, Rio de Janeiro são municípios que possuem graus variados de polarização em relação aos municípios vizinhos. No entanto, ser polarizador não significa ter um amplo mercado de trabalho de local, pois

[...] talvez ele não vá conseguir emprego em Santo Antônio de Pádua... o que acontece no Noroeste fluminense, maior empregador é a administração pública... [...]desafio pro instituto...[...] que mercado de trabalho que tem no interior? É o mercado da prefeitura... então, a gente tem que debater muito isso também, tem que conversar com setor produtivo...aqui em Pádua você ainda tem uns apontamentos, de umas empresas que podem absorver, mas não vão absorver todos os nossos alunos...esses alunos vão pra Macaé, Campos, Rio de Janeiro capital...[...] (DG-Santo Antônio de Pádua)

38 A qualificação do discente não garante, por si só, o emprego, uma vez que isso depende da estrutura produtiva local (MANFREDI, 2002). Não obstante, a Prefeitura aparece como importante empregadora em municípios do estado, o que emergiu na fala de alguns diretores. De acordo com DG-Pinheiral, a Administração Pública também aparece como a maior empregadora do município seguida pela própria unidade do Instituto Federal.

A cidade praticamente não tem fonte de emprego...né...só comércio local que é muito pequeno, cidade de 22 mil habitantes, é uma cidade-dormitório [...] então assim, $60 \%$ aí dos trabalhadores de Pinheiral na prática, eles moram em Pinheiral, mas trabalham em Volta Redonda, 20, 25\% trabalham em Piraí...Barra do Piraí...um pequeno número que realmente fica em Pinheiral...a Prefeitura é o maior empregador...o campus o segundo maior empregador do município...e o restante é basicamente comércio... (DG-Pinheiral)

Ademais, os formados pelos Institutos Federais buscam oportunidades em outras partes do estado e do País e isso não ocorre somente em municípios ou regiões com menor mercado de trabalho local. Alguns discentes formados na capital fluminense, apesar de possuírem uma maior possibilidade de ingressarem em um ramo de atividade econômica do município ou da Região Metropolitana, também buscam oportunidades distantes da capital, ao se empregarem em Macaé, por exemplo, em vista da indústria do petróleo lá existente. 
[...] É, nós temos, é, o campus Rio de Janeiro, em particular, tem seus, todos os seus cursos voltados pra cursos de base química e biológica, né, e um curso especificamente na área de informática que tem, foram gerados ou tiveram sua proposta sempre em base a levantamento de informações e necessidades da nossa macrorregião, né, então assim, ele atende efetivamente a perspectiva do município e da região, considerando que são cursos que atendem ao mercado, às indústrias e às empresas que nós temos no entorno, tanto do município, como da macrorregião....na região metropolitana e fora dela...alcança Macaé, alunos que estagiaram ou que fizeram, acabaram, a partir de concurso trabalhando em Angra dos Reis, é... alguns que trabalham na plataforma na área de petróleo, na plataforma de Campos e Macaé, então a gente atinge uma abrangência bastante grande...antiga siderúrgica nacional, na CSN, e em outras áreas, área de alimentos vai trabalhar em cervejarias, que não estão no centro, efetivamente, em região limítrofes, ou fora mesmo da região limite da região metropolitana... (DG-Rio de Janeiro) região e do estado, em especial na área de química, uma vez que o município de Nilópolis não tem uma base produtiva que a absorva. Em Engenheiro Paulo de Frontin outra estratégia para o desenvolvimento local e regional tem se desenvolvido na unidade, em especial com a criação do tecnólogo de Jogos Digitais. Ao indagarmos sobre se os cursos ofertados no campus atendem às perspectivas de desenvolvimento do município e da região, o entrevistado respondeu:

Eu vou dizer pra você que não, sabe porque que não? Porque...é...que não e que sim, porque se você pegar o curso... o projeto de curso, nós fizemos uma pesquisa empírica, tá... e essa pesquisa, fomos nas escolas, e ela aponta, principalmente nas escolas, o interesse pelo aluno estudar tecnologia, isso tá lá, a gente colocou as opções, a gente testou naquela pesquisa, naquela oportunidade, a gente testou o interesse por áreas como, é... agrícola, é... turismo e a gente percebeu que o jovem ele apontava, a leitura que a gente fez daqueles dados, é que o jovem apontava interesse por não reproduzir o que tava posto, pelo menos aos atores perguntados na entrevista, naquele momento, então, nesse caso, sim... e não, porque uma estratégia conforme prevê a lei de criação dos Institutos, da abordagem dos arranjos produtivos locais, lá diz, a indução de arranjo, fala sobre, é...sobre arranjos produtivos locais...e aí a gente tá na perspectiva de indução de arranjo, então essa indução de arranjo é algo pra você me perguntar pra daqui a 10 anos, eu acho...ou pra quem estiver sentado aqui... e aí induziu o arranjo de fato? A gente percebe... tem um arranjo ligado ao eixo de hospitalidade e lazer e pra esse eixo nós atendemos com curso de Formação Inicial e Continuada...[...] não deixamos de atender o arranjo produtivo, nós oferecemos cursos de Formação Inicial e Continuada...cursos de ... recepcionista em hospedagem, auxiliar administrativo...são dois eixos aí que a gente forma...[...] (DG-Engenheiro Paulo de Frontin)

Assim, conforme prevê a Lei de criação dos Institutos Federais (Lei no⒒892, de dezembro de 2008), é papel da instituição orientar sua oferta formativa em benefício da consolidação e fortalecimento dos arranjos produtivos, sociais e culturais locais, identificados com base no mapeamento das potencialidades de desenvolvimento socioeconômico e cultural, o que é realizado pela unidade com a oferta de cursos de Formação Inicial e Continuada. No entanto, na lei, não se faz menção à indução de estabelecimento de arranjo produtivo local como papel do Instituto. Por isso, a estratégia de indução de arranjo pode trazer os resultados esperados, com alavancamento de oportunidades locais, o adensamento produtivo a partir da produção de jogos digitais, mas a "sobre especialização" do espaço pode ser um risco: é passível de engessar a 
localidade, o que dificulta o desenvolvimento de novas capacitações, em resposta às alterações ocorridas no mercado (DINIZ \& CROCCO, 2006).

Não obstante, relembramos que uma das razões que serviram para justificar a desconcentração da rede federal de ensino profissional fora a ampliação do acesso à educação profissional, e a verticalização do ensino, da população de municípios e regiões mais carentes na oferta dessas formações. Com isso, um dilema que apareceu na fala da DG-Engenheiro Paulo de Frontin foi sobre como o modo de seleção dos alunos ingressantes na graduação pode ser um problema para se privilegiar a população local e regional:

[...]O SiSU escancara a formação da educação básica local... não se fala que a educação tá ruim, no Rio, não sei o quê...porque o daqui, não quer dizer que os garotos não tentem estudar aqui...eles tentam, mas ele vai bater de frente com o ENEM, com a nota do ENEM, com o cara de São Paulo, com o garoto do Rio... aí tudo fica às claras, as diferenças de tudo, de você viver numa capital...tudo isso vem à tona....através do ENEM...[...] (DG-Engenheiro Paulo de Frontin)

Recordamos que em Engenheiro Paulo de Frontin dois cursos regulares são oferecidos: o curso profissional de nível médio, na modalidade concomitante ou subsequente, de Informática para Internet e o curso de tecnólogo em Jogos Digitais, de nível superior. De acordo com DG-Engenheiro Paulo de Frontin, a maior parte dos discentes do curso profissional de nível médio é oriunda do município de Engenheiro Paulo de Frontin ou de municípios circunvizinhos. No entanto, os alunos do curso de graduação se originam de outros municípios do estado e, também, de outras unidades da federação.

Destaca a DG-Engenheiro Paulo de Frontin que o aluno do curso profissional de nível médio não alcança o nível superior nesse campus do Instituto Federal porque grande parte dos alunos tem a formação de ensino básico cursada em escolas da rede pública municipal ou estadual da localidade. Dessa forma, com a baixa qualidade dessa formação de ensino básico, o aluno, apesar de ter cursado o curso técnico no campus, não consegue ingressar no tecnólogo ofertado pela unidade.

Tal dificuldade acontece porque, de modo geral, o discente que realizou o curso técnico no campus obtém, no Exame Nacional do Ensino Médio (ENEM), nota insuficiente para concorrer com candidatos oriundos de capitais e outros estados que possuem melhor formação básica e, consequentemente, obtêm melhores notas no ENEM. À vista disso, acredita a DG-Engenheiro Paulo de Frontin que a oferta do curso integrado de nível médio, ou seja, as disciplinas integradas do curso técnico com as propedêuticas do ensino médio, o aluno da localidade teria maiores chances de ingressar no nível superior ofertado pelo campus.

Essa problemática se aguça quando observamos que uma das premissas do Instituto Federal é a verticalização do ensino. Pretende-se com a verticalização que os cursos profissionais de nível médio sejam o embrião para a criação de cursos superiores e, também, de cursos de pós-graduação. Nessa medida, almeja-se que a verticalização do ensino propicie ao discente a possibilidade de cursar as etapas de seu percurso formativo no próprio campus, desde a formação técnica até, quando possível, a pós-graduação.

Assim, pela adoção do SiSU como mecanismo de seleção, nesse caso citado, os alunos da localidade que cursam o ensino técnico na unidade, em grande parte, não prosperam ingressar no nível superior ofertado no campus. Tem-se, dessa maneira, frustrada a intenção de se privilegiar a população local e regional na formação ofertada pelo campus, 
ao menos na perspectiva delineada pela desejada verticalização do ensino e pelas razões que justificaram a expansão da rede federal de ensino profissional.

No que tange ao empreendedorismo, ainda se nota que há desafios a serem enfrentados. É interessante apontar que a "cultura regional" aparece como uma das razões que explicaria a falta de capacidade empreendedora dos formados pelo Instituto, na visão de um dos gestores da unidade Bom Jesus do Itabapoana.

[...] Do técnico ainda é muito tímido, acho que isso é cultural da região...CTA tem três alunos que empreenderam então, temos, isso ainda que está um pouco tímido, acho que é muito cultural, as pessoas não se projetam tanto, ainda... (DE-Bom Jesus do Itabapoana)

Destaca-se, no entanto, que esse é um dos papéis do instituto: estimular o empreendedorismo. Parece que ainda não há uma política institucional que fortaleça o empreendedorismo na formação dos profissionais e, portanto, na mudança da "cultura". Ao perguntarmos sobre empreendedorismo ao entrevistado em Cabo Frio, fomos informados de que se está "pensando em colocar no currículo o empreendedorismo, encaixar dentro das disciplinas" (DG-Cabo Frio), ainda que isso já aconteça, sem esse grau de formalização.

51 Outro aspecto abordado se refere às mudanças na base produtiva local e regional. Aparentemente, determinados cursos técnicos podem perder a capacidade de atrair alunos, em vista das modificações produtivas locais e regionais:

Bom, do município em parte, mas da região, sim, e todos eles têm uma demanda razoável, né, o curso de agropecuária, que aqui já foi uma região agrícola, o vale do ciclo café, depois a bovinocultura de leite, agora um pouco bovinocultura de corte, mas aqui na cidade de Pinheiral e Volta Redonda, que tá muito próxima, até Barra do Piraí, da década de 50 pra cá, o processo de industrialização acabou transformando essa área que era agrícola ou de pecuária, né, uma área mais industrial, então a demanda por técnicos na área, é, agrícola, diminuiu muito, né, mas os outros cursos que nós temos de informática, de administração, o próprio curso de agroindústria, meio ambiente são cursos que atendem à demanda solicitada...

[...]

Pois é né, ele historicamente tem uma importância ímpar na região, por ser um colégio na área de agropecuária, né, se a gente pensar até de 70, 80, a parte da agropecuária, tinha um peso significativo no estado do Rio, de lá pra cá tem caindo, e ao mesmo tempo a escola resolveu se reinventar, vamos atuar em outros cursos, então, isso vem sim contribuindo pra região como um todo...

[...]

Número de alunos aumentou [...] a gente oferecia 160 vagas por ano, praticamente pra 5 turmas de agropecuária, só, que era o único curso que tinha até 2000..2002..eu acho...e a gente não conseguia completar as 160 vagas e, no final das contas, é forma uns 40, 45 alunos...só em agropecuária. E assim a escola tinha 200, 250 alunos, em média...eu assumi há 2 anos atrás, a escola tinha 485 alunos, já oferece um pouco mais de 160 vagas, hoje a gente oferece 250 vagas...240...250...e tem fila de espera. Hoje não sobra vaga, né [...] ]então, quando eu assumi há dois anos atrás a gente tinham 485 alunos, hoje nós temos 585...agora no segundo semestre então mais 60 alunos...então a gente já vai passar de 600 de alunos... (DG-Pinheiral)

52 Dessa forma, a expansão da rede, o aporte de recursos, a contratação de profissionais, dentre outros aspectos, tem possibilitado o aumento do número de estudantes que ingressam nos Institutos Federais. Assim, os diretores ressaltam a importância não apenas da expansão, mas também da manutenção da rede federal de ensino na contribuição para o desenvolvimento, não apenas do estado do Rio de Janeiro, mas de todo o País. 


\section{Considerações Finais} desenvolvimento local e regional, a respeito da relevância dos institutos federais no desenvolvimento territorial do território fluminense. Os resultados da pesquisa apontam que os diretores entendem que as unidades dos institutos são importantes vetores no desenvolvimento socioeconômico do estado, ainda que haja dificuldades na consecução da política pública.

Considerando-se que a política pública de Educação empreendida pelo Governo Federal, a partir da criação dos Institutos Federais em 2008, incorporou o território como base fundamental para orientar as atividades dos institutos federais do Rio de Janeiro, é importante reconhecer a relevância dos atores locais que concretizam, ou buscam concretizar, as aspirações que fundamentam essas instituições. Por outro lado, as unidades dos institutos federais no território fluminense se revelam importantes, na medida em que se amplia a densidade organizacional dos territórios (RÜCKERT, 2005, p. 87), dotando diferentes localidades de novos instrumentos no desenvolvimento.

Ademais, tais ações resultam na elevação da educação da população, na ampliação das possibilidades de se gerar inovações, na constituição de redes colaborativas que articulam os atores e agentes sociais locais e regionais, na atuação em rede que mobiliza municípios circunvizinhos etc. Nessa medida, e na perspectiva aqui referenciada, os Institutos Federais se constituem como mais um vetor do fortalecimento necessário para o desenvolvimento de regiões inteligentes (FERRÃO, 2002).

Assim, sob novas formas de ação, o Estado tem fomentado o engajamento dos territórios para a competição econômica nas escalas subnacionais (BECKER, 2009), ao guarnecê-las de instituições educativas que sirvam não apenas para formar profissionais para a economia, mas que atuem no desenvolvimento das localidades e regiões. Dessa forma, entende-se que os atores locais e regionais são imprescindíveis no desenvolvimento local e regional, posto serem os que capitaneiam novos processos, novas possibilidades para as comunidades locais e regionais.

\section{BIBLIOGRAFIA}

ALBAGLI, Sarita; MACIEL, Maria Lucia. Informação e conhecimento na inovação e no desenvolvimento local. Ci. Inf., Brasília, v. 33, n. 3, p.9-16, set./dez, 2004. Disponível em: <http:// www.scielo.br/scielo.php?script=sci_arttext\&pid=S0100-19652004000300002\&lng=en\&nrm=iso>. Acesso em: 10 abr. 2019.

ABRUCIO, Fernando Luiz. A dinâmica federativa da educação brasileira: diagnóstico e propostas de aperfeiçoamento. OLIVEIRA, Romualdo P. SANTANA, Wagner. Educação e federalismo no Brasil: combater as desigualdades, garantir a diversidade. Brasília: UNESCO, 2010. 
ALBUQUERQUE, Francisco. El enfoque del desarollo económico local. Cuaderno de Capacitación, n. 1, Serie: Desarrollo Económico Local y Emplabilidad Programa AREA - OIT em Argentina - Italia Lavoro. Buenos Aires: Organización Internacional del Trabajo, 2004. Disponível em: <http:// www.flacsoandes.edu.ec/sites/default/files/agora/files/1251776298.area_enfoque_del_0.pdf>. Acesso em: 15 abr. 2019.

BECKER, Bertha K. O governo do território em questão: uma perspectiva a partir do Brasil. Parc. Estrat. Brasília: v. 14, n. 28, 2009.

BONI, V; QUARESMA, S. Aprendendo a entrevistar: como fazer entrevistas em Ciências Sociais. Revista Eletrônica dos Pós-Graduandos em Sociologia Política da UFSC, v. 2, n. 1 (3), jan.-jul./2005, p. 68-80.

DINIZ, Clélio Campolina; CROCCO, Marco A. (Orgs.). Economia regional e urbana. Belo Horizonte: Editora UFMG, 2006.

FERRÃO, João. Inovar para desenvolver: o conceito de gestão de trajectórias territoriais de inovação. Interações (Campo Grande), [S.l.], fev. 2016. ISSN 1984-042X. Disponível em: <http:// www.interacoes.ucdb.br/article/view/573>. Acesso em: 29 abr. 2019. doi:http:// dx.doi.org/10.20435/interacoes.v3i4.573.

MANFREDI, Silvia Maria. Educação Profissional no Brasil. São Paulo: Cortez, 2002.

MINAYO, M. C. de S. (Org.). Pesquisa social: teoria, método e criatividade. Petrópolis: Vozes, 1994.

RÜCKERT, A. A. Reforma do Estado, reestruturações territoriais, desenvolvimento e novas territorialidades. I Seminário Nacional sobre Múltiplas Territorialidades. Porto Alegre; Canoas: Programa de Pós-Graduação em Geografia-Ufrgs; Curso de Geografia, lbra, 2004. . O processo de reforma do Estado e a Política Nacional de Ordenamento Territorial. BRASIL. Para pensar uma Política Nacional de Ordenamento Territorial. Brasília: Ministério da Integração Nacional, p. 31-39, 2005.

SEN, Amartya. Desenvolvimento como liberdade. Trad. de Laura Teixeira Motta; revisão técnica Ricardo Doninelli Mendes. São Paulo: Companhia das Letras, 2010.

SOUZA, Mauro Sergio. P. S. Os Institutos Federais de Educação, Ciência e Tecnologia como vetores de desenvolvimento territorial no estado do Rio de Janeiro. Dissertação (Mestrado). Niterói, 2016. $233 \mathrm{p}$.

VÁZQUEZ-BARQUERO, A. Endogenous development. London and New York: Routledge. 2002.

BRASIL. Lei nº11.892. Brasília, dezembro, 2008.

\section{RESUMOS}

O Governo Federal, desde 2005, estabeleceu uma política nacional no âmbito da Educação que visou guarnecer diferentes localidades e regiões do país de unidades federais de ensino profissional. Para isso, estabeleceu um programa de expansão da rede federal de ensino dividido em três fases, cuja a terceira se encontra inconclusa, com o objetivo de desconcentrar a rede. Além de buscar fortalecer a educação nacional, em vista da magnitude com que a expansão transcorreu, o programa buscou engajar as escalas subnacionais para a competição econômica, corolário das transformações próprias do capitalismo contemporâneo. Preceitua-se que essas instituições federais de ensino devam corresponder, nas escalas locais e regionais, a demandas da economia, além de formar profissionais qualificados para atuarem local ou regionalmente. Esse papel é efetivamente reforçado com a criação dos Institutos Federais de Educação, Ciência e 
Tecnologia, em 2008. O nome dessas instituições não é sem sentido: devem buscar articular a educação, em especial a educação profissional, com a produção de ciência e tecnologia. Ter-se-ia, então, uma mudança do papel das antigas escolas técnicas federais que, neste século, precisam atender ao dinamismo e à competição econômica crescente, sobretudo a partir da profusão de inovações técnicas e tecnológicas. Nesse sentido, o Estado brasileiro reforça seu papel como agente na economia nacional, ao buscar atender às necessidades econômicas das diversas localidades do País. A partir dessas considerações, o artigo apresenta um panorama da percepção de gestores de unidades dos Institutos Federais de estado do Rio de Janeiro na relevância dessas instituições para o desenvolvimento local e regional. A importância dos institutos aparece fortemente nos discursos desses gestores, ainda que dificuldades transpareçam no cotidiano das atividades empreendidas pelas instituições, o que aponta para avanços e obstáculos no papel por elas desempenhados.

Depuis 2005, le gouvernement fédéral a mis en place une politique nationale d'éducation visant à garantir différentes localités et régions du pays à partir des unités fédérales d'enseignement professionnel. À cette fin, il a mis en place un programme d'expansion du réseau fédéral d'éducation divisé en trois phases, dont la troisième est inachevée, afin de déconcentrer le réseau. En plus de chercher à renforcer l'éducation nationale, compte tenu de l'ampleur de l'extension, le programme visait également à faire participer les échelles infranationales de concurrence économique, corollaire des transformations typiques du capitalisme contemporain. Ces établissements d'enseignement fédéraux sont censés répondre, aux niveaux local et régional, aux exigences de l'économie, en plus de former des professionnels qualifiés pour travailler sur le plan local ou régional. Ce rôle est effectivement renforcé par la création des Instituts fédéraux de l'éducation, de la science et de la technologie en 2008. Le nom de ces institutions n'a pas de sens: elles doivent chercher à articuler l'éducation, en particulier la formation professionnelle, avec la production de la science et de la technologie. Le rôle des anciennes écoles techniques fédérales, qui au cours de ce siècle, doivent réagir au dynamisme et à la concurrence économique grandissante, en particulier de l'abondance d'innovations techniques et technologiques, changerait alors. En ce sens, l'État brésilien renforce son rôle d'agent dans l'économie nationale en cherchant à répondre aux besoins économiques des différentes localités du pays, à partir de quoi cet article donne un aperçu de la perception des responsables des unités des Instituts fédéraux de Rio. la pertinence de ces institutions pour le développement local et régional. L'importance des instituts apparaît fortement dans les discours de ces responsables, bien que des difficultés apparaissent dans les activités quotidiennes des institutions, ce qui laisse présager des avancées et des obstacles dans leur rôle.

El Gobierno Federal, desde 2005, estableció una política nacional en el ámbito de la Educación que pretendía guarnecer diferentes localidades y regiones del país de unidades federales de enseñanza profesional. Así, ha creado un programa de expansión de la red federal de enseñanza dividido en tres fases, cuya tercera se encuentra inconclusa, con el objetivo de desconcentrar la red. Además de buscar fortalecer la educación nacional, en vista de la magnitud con que la expansión transcurrió, el programa buscó involucrar las escalas subnacionales para la competencia económica, corolario de las transformaciones propias del capitalismo contemporáneo. Se prevé que esas instituciones federales de enseñanza deban corresponder, en las escalas locales y regionales, a demandas de la economía, además de formar profesionales calificados para actuar local o regionalmente. Este papel es efectivamente reforzado con la creación de los Institutos Federales de Educación, Ciencia y Tecnología, en 2008. El nombre de esas instituciones no es sin sentido: deben buscar articular la educación, en especial la educación profesional, con la producción de ciencia y tecnología. Se tendría entonces un cambio del papel de las antiguas escuelas técnicas federales que en este siglo necesitan atender al dinamismo ya la competencia económica creciente, sobre todo a partir de la profusión de innovaciones técnicas y 
tecnológicas. En este sentido, el Estado brasileño refuerza su papel como agente en la economía nacional, al buscar atender las necesidades económicas de las diversas localidades del país. El artículo presenta un panorama de la percepción de gestores de unidades de los Institutos Federales de estado del Río de enero en la relevancia de esas instituciones para el desarrollo local y regional. La importancia de los institutos aparece fuertemente en los discursos de esos gestores, aunque dificultades ocurran en el cotidiano de las actividades emprendidas por las instituciones, lo que apunta avances y obstáculos en el papel que desempeñan.

Since 2005, the Federal Government has established a national education policy aimed at garnishing different localities and regions of the country from federal vocational education units. To this end, it established a program of expansion of the federal network of education divided into three phases, the third of which is unfinished in order to deconcentrate the network. In addition, to seek to strengthen national education, in view of the magnitude with which the expansion occurred, the program engaged with the subnational scales for economic competition, a corollary of the transformations typical of contemporary capitalism. These federal educational institutions are expected to correspond at local and regional scales, to the demands of the economy. Moreover, to train professionals qualified to work locally or regionally. This role is effectively reinforced by the creation of the Federal Institutes of Education, Science and Technology in 2008. The name of these institutions is not meaningless: they must seek to articulate education, especially vocational education, with the production of science and technology. There would then be a change in the role of the old federal technical schools which, in this century, need to respond to the dynamism and increasing economic competition, especially from the profusion of technical and technological innovations. In this sense, the Brazilian State reinforces its role as an agent in the national economy by seeking to meet the economic needs of the different localities of the Country. Overall, the article presents an overview of the perception of managers of units of the Federal Institutes in the state of Rio de Janeiro, and the relevance of these institutions to local and regional development. The importance of the institutes appears strongly in the discourses of these managers, although difficulties appear in the daily activities of the institutions, which points to advances and obstacles in the role they play.

\section{ÍNDICE}

Mots-clés: Déconcentration, réseau fédéral d'éducation, enseignement professionnel, développement local et régional

Palavras-chave: Desconcentração, Rede Federal de Educação, Ensino Profissional, Desenvolvimento Local e Regional

Palabras claves: Desconcentración, Red Federal de Enseñanza, Enseñanza Profesional, Desarrollo local y regional

Keywords: Deconcentration, Education Federal network, Vocational Education, Local and Regional Development

\section{AUTOR}

\section{MAURO SERGIO PINHEIRO DOS SANTOS DE SOUZA}

Instituto Brasileiro de Geografia e Estatística. Coordenação de Geografia. Geógrafo. Mestre em Geografia - UFF

E-mail: maurospss@gmail.com 